\title{
Percepções do ambiente, condições psicológicas e de qualidade de vida em habitantes de ocupações irregulares de área de manguezais na Baixada Santista, SP, Brasil
}

\author{
Environmental perceptions, psychological conditions and \\ inhabitants' quality of life in irregular occupation in the \\ mangrove areas in Baixada Santista, SP, Brazil
}

Nancy Ramacciotti de Oliveira-Monteiro ${ }^{\mathrm{a}}$

Débora Santos Silva ${ }^{b}$

${ }^{a}$ Doutora em Psicologia Social,Coordenadora do Laboratório de Psicologia Ambiental e Desenvolvimento Humano, Universidade Federal de São Paulo (LADH/UNIFESP-BS), Santos, SP, Brasil End. Eletrônico: nancy.unifesp@gmail.com

${ }^{b}$ Bacharel em Ciências e Tecnologia do Mar, Universidade Federal de São Paulo, Santos, SP, Brasil. End.Eletrônico: deborah_s.s@hotmail.com

doi:10.18472/SustDeb.v9n3.2018.16914

Recebido em 05.10.2017

Aceito em 27.06.2018

ARTIGO - VARIA

\section{RESUMO}

Os manguezais são importantes ecossistemas que muitas vezes estão em intensa interação com ambientes de urbanização irregular e não planejada. Com o objetivo de verificar percepções do ambiente, condições psicológicas e de qualidade de vida em habitantes de ocupações irregulares de área de manguezais na Baixada Santista (SP), foram investigados 30 moradores de um bairro de manguezal através do Whoqol-Bref (World Health Organization Quality of life-Abbreviated Scale), ASR (Adult Self-Report for ages 18-59) e de um questionário sobre percepção ambiental. A análise descritiva dos resultados indicou: percepção ambiental marcada por valor positivo do manguezal, importância de preservação, nomeações de espécies diversas e de componentes físicos; problemas psicológicos em faixas clínicas em mulheres mais jovens da amostra; e classificação de qualidade de vida: boa (domínios físico, psicológico e relações sociais) e regular (domínio de meio ambiente). A percepção ambiental acentuada e a regularização fundiária promovida no bairro podem estar relacionadas à boa saúde e qualidade de vida dos participantes.

Palavras-chave: Manguezal; Qualidade de vida; Percepção ambiental; Condições psicológicas.

\footnotetext{
ABSTRACT

Mangroves are important ecosystems that sometimes may have intense interaction with irregular unplanned urbanization environments. The objective of this work is to analyze the perceptions of the environment, psychological conditions and inhabitants' quality of life within irregular occupations in the
} 
mangrove areas of the Baixada Santista (SP). Thirty residents of a mangrove neighborhood were recruited and answered the following instruments: World Health Organization Quality of life - Abbreviated Scale (WHOQOL - Bref), Adult Self-Report for ages 18-59 (ASR) and an environmental perception survey. The data descriptive analysis indicated: environmental perception marked by positive values attributed to the mangrove, importance of preservation, appointments of various species and physical components; problems of clinical psychology affecting young women, and quality of life classified as good (physical, social and psychological domains) and regular (environmental domain). The accentuated environmental perception and the regularization of the occupations may be related to the good health and quality of life of the participants.

Keywords: Mangrove; Quality of life; Environmental perception; Psychological conditions.

\section{INTRODUÇÃO}

Como ecossistemas de transição entre a terra e o mar, os manguezais possuem importantes funções ecológicas nas regiões costeiras, agindo como berçário da biodiversidade marinha e estuarina, e sendo retentores de sedimentos e erosão, além de filtradores de poluentes na água (QUEIROZ; MEIRELES; HERAS, 2012). Com vista à sua preservação, o manguezal foi instituído como Área de Preservação Permanente (APP) pela Lei no. 12.651, de 25 de maio de 2012 (BRASIL, 2012), que permite somente ocupações ou atividades humanas em seu território se essas forem de pouco impacto e de utilidade pública (BORGES; COELHO JÚNIOR; REZENDE, 2008).

Algumas comunidades tradicionais utilizam os manguezais como fonte de sobrevivência, como no caso de populações caiçaras e de pescadores artesanais. $O$ trabalho sobre a explotação dos manguezais de Castro, Menezes e Moreira Júnior (2009) apontava que as atividades realizadas por essas populações tradicionais não acarretavam grande impacto ao ecossistema do manguezal, pois os seus costumes apresentavam regras baseadas em conhecimentos ecológicos sobre a capacidade de resiliência do ambiente. Por outro lado, outros estudos indicaram problemas relativos a ocupações irregulares em manguezais, tidas como causadoras de diversos impactos negativos (LIMA; OLIVEIRA, 2011; SALES; SILVA; CLEMENTINO, 2006).

Em investigações sobre a relação entre sociedade e mangue, Sales, Silva e Clementino (2006) destacaram impactos negativos decorrentes de expansão urbana caracterizada por moradores geralmente prestadores de serviços em centros urbanos ou arredores. Esses moradores teriam dificuldades de percepção sobre a importância dos manguezais. Por outro lado, populações cujas atividades econômicas e sociais funcionam dentro do ambiente e em harmonia com ele, tendem a possuir atitudes ambientais mais sustentáveis (UNESCO, 1971).

As atitudes ambientais de um povo são respostas à visão de mundo e ao estilo de vida que possui. Essas atitudes podem ser baseadas em valores positivos que são permeados por uma identificação emocional com o ambiente. $\mathrm{O}$ termo "topofilia" refere-se ao elo afetivo entre a sociedade e o meio ambiente. Esse laço é enriquecido por conhecimentos da história local, com uma relação mais direta com os componentes do ambiente, e com a percepção da beleza e da importância do lugar (TUAN, 1980).

Elos afetivos com os manguezais são muitas vezes prejudicados na cultura brasileira, que tende a perceber o mangue como um local sujo e/ou fétido, onde depósitos de lixo são constantes (ALVES, 2001). Essa é uma ideia que, juntamente à falta de informações pertinentes à importância do manguezal, leva a atitudes ambientais destrutivas (UNESCO, 1971). Por conseguinte, para ações de planejamento de mudanças promotoras de um futuro sustentável dos manguezais brasileiros, é fundamental conhecer percepções ambientais de seus habitantes, sejam das cercanias ou moradores dos próprios ambientes de manguezais (MARIN, 2008; PALMA, 2005; UNESCO, 1971).

O litoral da Baixada Santista, região metropolitana do estado de São Paulo, é um espaço marcado por uma alta proporção de ecossistemas e adensamento urbano, característica com potencial condição para conflitos (SECRETARIA DO MEIO AMBIENTE DO ESTADO DE SÃO PAULO [SMA], 2013). Paisagens 
marinhas e costeiras, características dessa região, são bastante valorizadas pelo mercado imobiliário, pois muitas pessoas estão dispostas a pagar mais por residências com vistas para esses locais (WHITE et al., 2016). Por outro lado, e de forma contrastante, também existe interesse de pessoas com menores condições econômicas por residir em áreas próximas a regiões costeiras (WHITE et al., 2016). As terras nas áreas litorâneas são valorizadas e a especulação imobiliária costuma ser grande. Por sua vez, populações de baixa renda acabam por ocupar áreas desprezadas pelo mercado formal, como áreas de risco ou áreas legalmente protegidas, como é o caso dos manguezais (SMA, 2013).

Investigações indicam que a expansão da "mancha urbana" pode causar redução e fragmentação das áreas de manguezais (CUNHA-LIGNON et al., 2009), causando a poluição do ambiente (MOREIRA JÚNIOR; CASTRO; MENEZES, 2009) e contribuindo para o desequilíbrio da zona costeira, devido à perda de suas funções ecológicas (ARASAKI et al., 2008). Os manguezais da Baixada Santista são os maiores do litoral paulista e em suas áreas há muitas ocupações irregulares (LUZ, 2006). Em estudo sobre recuperação desses manguezais, Menezes et al. (2005) mostraram que devido à forte pressão antrópica que esse ecossistema vinha sofrendo, somente $40 \%$ da sua área original encontrava-se em um bom estado de conservação.

Contrárias às legislações ambientais, as ocupações irregulares de áreas de manguezal crescem sem uma infraestrutura adequada para a habitação, tendo que lidar com o solo impróprio, marés que causam alagamentos em épocas de chuva e incertezas de possíveis desocupações (LUZ, 2006). Esses fatores podem refletir na qualidade de vida e em condições emocionais dos moradores, pois levam a acreditar que suas necessidades não estão totalmente satisfeitas ou que oportunidades lhes estão sendo negadas (PEREIRA et al., 2006).

É consenso que o ambiente interage na saúde física e mental das pessoas (WHITE et al., 2016). Os mecanismos ambientais ligados à promoção da saúde são a redução do estresse, incentivo a atividades físicas e interações sociais e a qualidade ambiental (HARTIG et al., 2014). Vale destacar o estudo de White et al. (2016) que indicou que indivíduos que viviam perto da costa eram mais saudáveis e mais felizes do que aqueles que viviam no interior, principalmente no caso de populações mais pobres, já que a zona costeira pode oferecer maiores espaços de lazer e de promoção de saúde, de forma gratuita.

No contexto dessas colocações, este estudo traz como proposta investigar condições de vida de habitantes dessas ocupações irregulares de manguezais, com avaliação das percepções do ambiente, entendidas como uma "tomada de consciência e compreensão do homem do meio ambiente" (WHYTE, 1978, p. 18); de condições psicológicas, abrangendo problemas internalizantes (emocionais), problemas externalizantes (comportamentais) e meios adaptativos (competências humanas de lidar com o meio ambiente); e de qualidade de vida entendida como a "percepção do indivíduo sobre a sua posição na vida, no contexto da cultura e dos sistemas de valores nos quais ele vive, e em relação a seus objetivos, expectativas, padrões e preocupações" (THE WHOQOL GROUP, 1994, p. 1.405).

\section{MÉTODO}

Foram investigados 30 adultos, de ambos os sexos, moradores da área de manguezal do Bairro Caieiras, do município de Praia Grande (SP), que residiam no local há, pelo menos, um ano. Esses participantes foram escolhidos por critérios de conveniência e acessibilidade. Buscou-se equilíbrio no número dos participantes nas variáveis sexo e faixa etária. A amostra foi caracterizada por classe econômica por meio do Critério Brasil (ASSOCIAÇÃO BRASILEIRA DE EMPRESAS DE PESQUISA, 2015).

Com mais de 25 anos de existência, o Bairro Caieiras adentra o manguezal do Parque Municipal Piaçabuçu, uma área de $442 \mathrm{mil} \mathrm{m}^{2}$ envoltos por manguezal (SECRETARIA DA HABITAÇÃO DO ESTADO DE SÃO PAULO, 2016). Por essa característica, o bairro também é chamado de "Ilha das Caieiras". Dados de 2016 indicavam que o bairro possuía cerca de oito mil habitantes (SECRETARIA DA HABITAÇÃO DO ESTADO DE SÃO PAULO, 2016). A cidade de Praia Grande, onde fica o Bairro Caieiras, é um dos nove municípios da Baixada Santista, Região Metropolitana do Estado de São Paulo (SMA, 2013). Com $2.373 \mathrm{~km}^{2}$, essa região metropolitana abriga em seu território o Bioma Mata Atlântica e ecossistemas associados (SMA, 2013). 
No Plano Diretor do município de Praia Grande, publicado em 2006, a área do Bairro Caieiras é demarcada como Zona Especial de Regularização (ZER). Nesse tipo de zona de assentamentos subnormais está previsto o desenvolvimento de programas de regularização pelo poder público (PRAIA GRANDE, 2006). Quando a zona de ocupação irregular é ampla e a área de invasão já possui infraestrutura instalada (como fornecimento de água e eletricidade), uma desocupação causa grande impacto social (LUZ, 2006).

Este estudo realizou um levantamento de condições psicossociais de habitantes de territórios com uma tripla qualidade: ser um manguezal, uma ocupação irregular e com proximidade a grandes centros de urbanização. O levantamento abarcou três frentes de avaliação: a de elementos de percepção ambiental, a de qualidade de vida e a de condições psicológicas (referentes a competências e problemas emocionais e comportamentais).

Os instrumentos utilizados foram: 1) Adult Self-Report for ages 18-59 (ASR); 2) Whoqol-bref; e 3) Questionário de Percepção Ambiental Manguezal (Qpam). O ASR é um dos instrumentos que compõem o Sistema de Avaliação Empiricamente Baseada de Achenbach (Aseba) (ACHENBACH; RESCORLA, 2010), contém 126 itens que avaliam competências e problemas psicológicos. As competências são avaliadas como funcionamento adaptativo (em termos de competência total, atividades e competência social investigando relacionamento com amigos e família, funcionamento educacional, situação de trabalho e relacionamento com o esposo/a ou companheiro/a).

Problemas psicológicos são classificados em problemas internalizantes (ou emocionais), problemas externalizantes (ou comportamentais) e problemas psicológicos. Os resultados do ASR são dados através de escores, que podem indicar ou não a sugestão de intervenções clínicas. Estudo de análise fatorial de escalas do ASR foi conduzido no Brasil por Lucena-Santos, Moraes e Oliveira (2014) e o instrumento encontra-se em processo de validação multicultural (IVANOVA et al., 2015; ROCHA; GAUY; SILVARES, 2012).

O Whoqol-bref é uma versão abreviada do Whoqol-100 para avaliação de qualidade de vida desenvolvida pelo Grupo de Qualidade de Vida da Divisão de Saúde Mental da OMS e traduzida no Brasil pelo Departamento de Psiquiatria e Medicina Legal da Universidade Federal do Rio Grande do Sul, com as 26 questões que obtiveram os melhores desempenhos psicométricos extraídas do Whoqol-100 e divididas em quatro domínios. São eles: físico (dor e desconforto), psicológico (sentimentos positivos e negativos, imagem corporal e aparência, autoestima, memória, concentração e capacidade de aprender e pensar), relações sociais (relações pessoais, apoio social e atividade sexual) e meio ambiente (segurança, ambiente no lar, recursos financeiros, cuidados de saúde e sociais, oportunidade e habilidade de adquirir informações, lazer, poluição, ruído, trânsito, clima e transporte).

Por sua vez, o Questionário de Percepção Ambiental Manguezal (Qpam) é um instrumento confeccionado para o estudo a partir de referências de Lucena e Freire (2014). A percepção ambiental dos participantes da pesquisa foi avaliada a partir desse instrumento, com questões derivadas da literatura a respeito das características do manguezal (BORGES; REZENDE; COELHO JÚNIOR, 2008; QUEIROZ; MEIRELES; HERAS, 2012) e sobre percepção ambiental (LUCENA; FREIRE, 2014; WHYTE, 1977). Essa percepção foi verificada em quatro domínios: o de informação (conhecimentos acerca do ambiente), o sensorial (conhecimento e relação com o ambiente), o de valores (valores afetivos e de lazer atribuídos ao ambiente) e de atitudes (experiências, opiniões e ações em relação à conservação do ambiente). Na percepção ambiental, esses domínios articulam-se e integram-se. Dessa maneira, por exemplo, os valores são construídos a partir das informações e da percepção sensorial, podendo a presença de valores conduzir atitudes positivas ou negativas a respeito do meio ambiente.

Após convites e aceites, de acordo com os procedimentos éticos, o Termo de Consentimento Livre e Esclarecido (TCLE) foi apresentado com as informações sobre a pesquisa para as devidas explicações e assinaturas. $O$ bairro possuía duas pequenas praças, ruas pavimentadas, uma capela católica, cerca de 20 igrejas evangélicas e pequenos comércios, além de um posto de saúde e uma escola em seu entorno. As abordagens foram feitas nesses locais e as aplicações dos instrumentos ocorreram em lugares com privacidade, o que foi previamente combinado com os entrevistados. 
Os resultados do ASR foram obtidos através do software ADM (Assessment Data Manager) da Bateria Aseba, que faz a análise dos escores das perguntas contidas no questionário para verificação de meios adaptativos, problemas internalizantes e externalizantes. Os resultados são classificados nas faixas: "não clínica / normal" (escores menores que 59), "limítrofe" (escores entre 60 e 63) e "clínica" (escores maiores que 64). As faixas limítrofe e clínica são indicativas de necessidade de intervenção, em diferentes graus.

Os dados obtidos pelo Qpam foram analisados por frequências de respostas de forma qualitativa para as questões fechadas. O modelo de Análise de Conteúdo (BARDIN, 2010) foi utilizado para análise das respostas à questão aberta, com leitura e organização dos aspectos importantes do texto comunicado pelos entrevistados, seleção das unidades de análise e classificação dos dados em categorias.

Os escores do Whoqol-bref foram analisados segundo indicativos disponibilizados pelo Whoqol-Group. Os dados foram descritos por meio de médias, desvio-padrão, medianas e frequências utilizando o programa estatístico IBM SPSS.

\section{RESULTADOS}

A amostra foi composta por 15 mulheres e 15 homens, 14 adultos jovens e 16 de meia idade, das classes econômicas B, C, D-E, com nível de escolaridade do analfabetismo ao ensino médio completo, sendo que $83 \%$ deles encontravam-se nas classes econômicas C, D-E.

Os resultados parciais de percepção ambiental, no domínio da informação (conhecimentos acerca do ambiente), mostraram que $43 \%$ da amostra sabia que o manguezal do bairro era protegido por alguma lei ambiental, e ao serem questionados sobre quais eram essas leis, nenhum participante soube dizer uma lei propriamente dita, como o Código Florestal ou Sistema Nacional de Unidades de Conservação (Snuc) que seriam as respostas adequadas. Porém, com exceção de $28,6 \%$ que não souberam citar nada específico, todos referiram órgãos executores do Sistema Nacional de Meio Ambiente (Sisnama) e órgãos fiscalizadores competentes como responsáveis pela proteção do manguezal do bairro. Quando foram questionados a respeito das fontes dessa informação, muitos dos participantes $(66,6 \%)$ informaram tê-la obtido de forma empírica (por observação, por alguém próximo ou por funcionários da prefeitura). Da amostra, 67\% relataram acreditar que a titularidade do terreno de manguezal do bairro era de posse da Marinha do Brasil, que também é um órgão com competência fiscalizadora, porém, os manguezais se caracterizam, na realidade, como bens da União.

A Figura 1 apresenta resultados em dados absolutos sobre percepção ambiental dos investigados, em termos de manifestações sobre quem seriam os responsáveis pela proteção do manguezal.

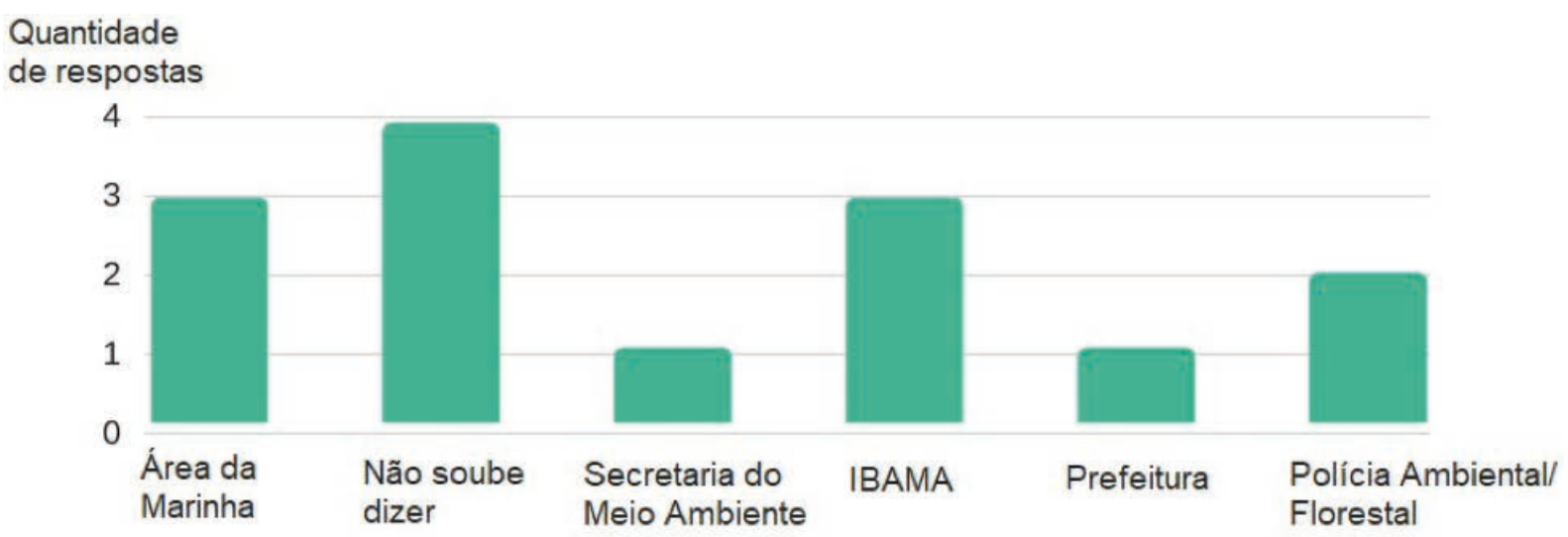

Responsáveis pela proteção do Manguezal

Figura 1 - Número de respostas sobre quem seriam os responsáveis pela proteção do manguezal. 
No domínio da percepção sensorial, $80 \%$ da amostra afirmou conhecer os animais e plantas presentes no manguezal do bairro. Quando questionados sobre quais eram as espécies conhecidas, houve uma grande diversidade citada, com prevalência do mangue (vegetação principal do manguezal) e do caranguejo (que é um de seus grandes símbolos). Apenas 17\% relataram fazer uso dessas espécies, sendo elas utilizadas para a alimentação, decoração e uso medicinal. Os principais elementos da paisagem citados foram o verde da vegetação, a lama, a água e os animais. Dos investigados, $73 \%$ afirmaram terem vindo morar no bairro na década de 1990, ou antes. Quando indagados se haviam notado modificações no manguezal do bairro ao longo do tempo, $60 \%$ manifestaram concordância; as principais modificações referidas foram a poluição e o desmatamento para construção de casas. Essas modificações pareceram avaliadas de forma ambivalente: alguns moradores manifestaram que as alterações tinham sido positivas para o bairro, por exemplo, por "diminuir a lama"; outros indicaram que as modificações haviam sido prejudiciais para o ecossistema.

A Figura 2 e a Figura 3 apresentam frequência de respostas em dados absolutos de elementos da percepção sensorial sobre o manguezal e percepção sensorial das modificações no ecossistema, respectivamente, pelos investigados.

\section{Quantidade de}

respostas

30

20

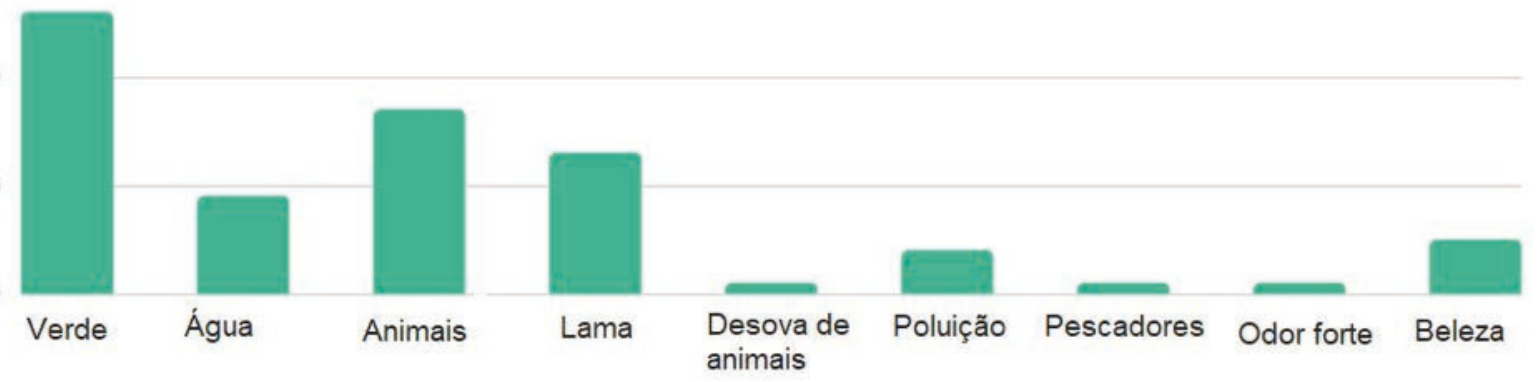

Elementos da paisagem

Figura 2 - Número de respostas sobre percepção sensorial dos elementos da paisagem do manguezal. Fonte: Autoras.

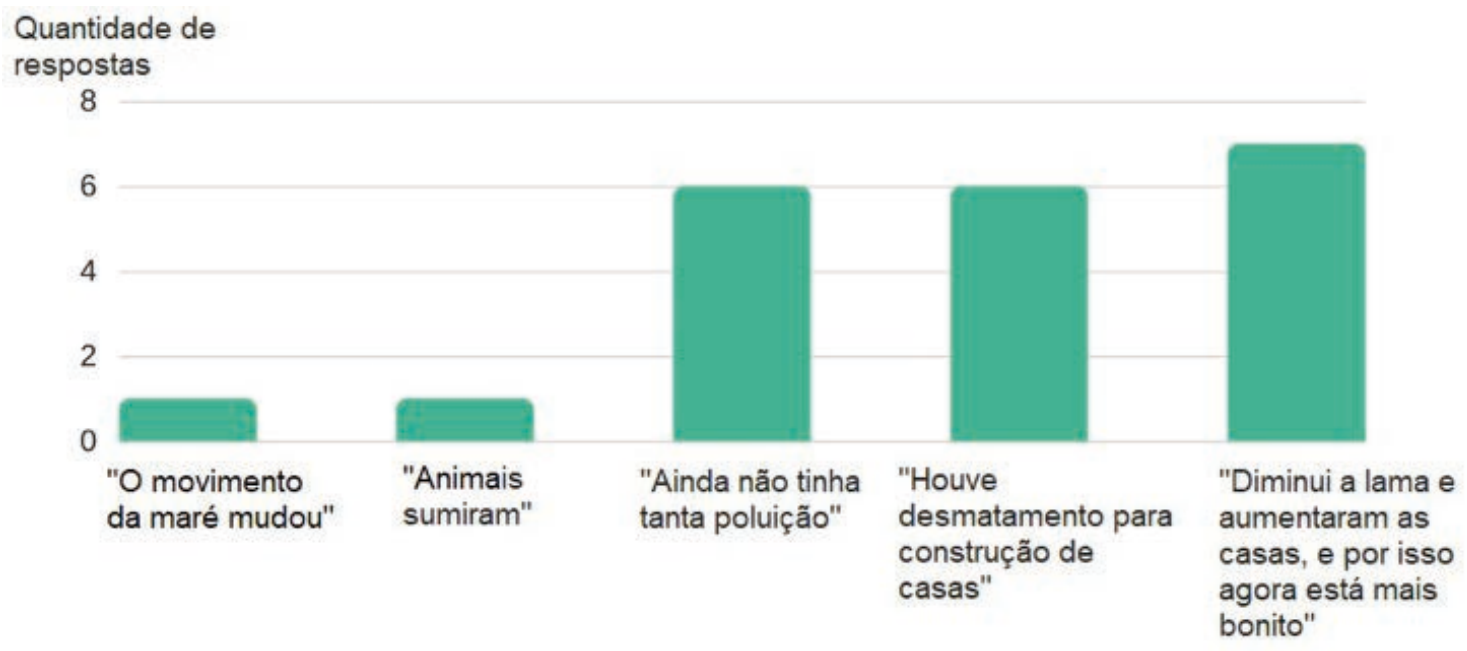

Modificações no manguezal

Figura 3 - Número de respostas sobre percepção sensorial acerca das modificações no manguezal 
Com relação ao domínio dos valores, $77 \%$ da amostra atribuiu valor positivo ao manguezal; para tanto, o motivo mais frequentemente referido foi o de sua função ecológica (por ser parte integrante da natureza). Dos investigados, $77 \%$ também atribuíram valor positivo ao bairro, citando sua tranquilidade e a boa relação entre os moradores.

A Figura 4 e a Figura 5 mostram dados absolutos (número de respostas) dos valores atribuídos pelos investigados ao manguezal e ao bairro, respectivamente.

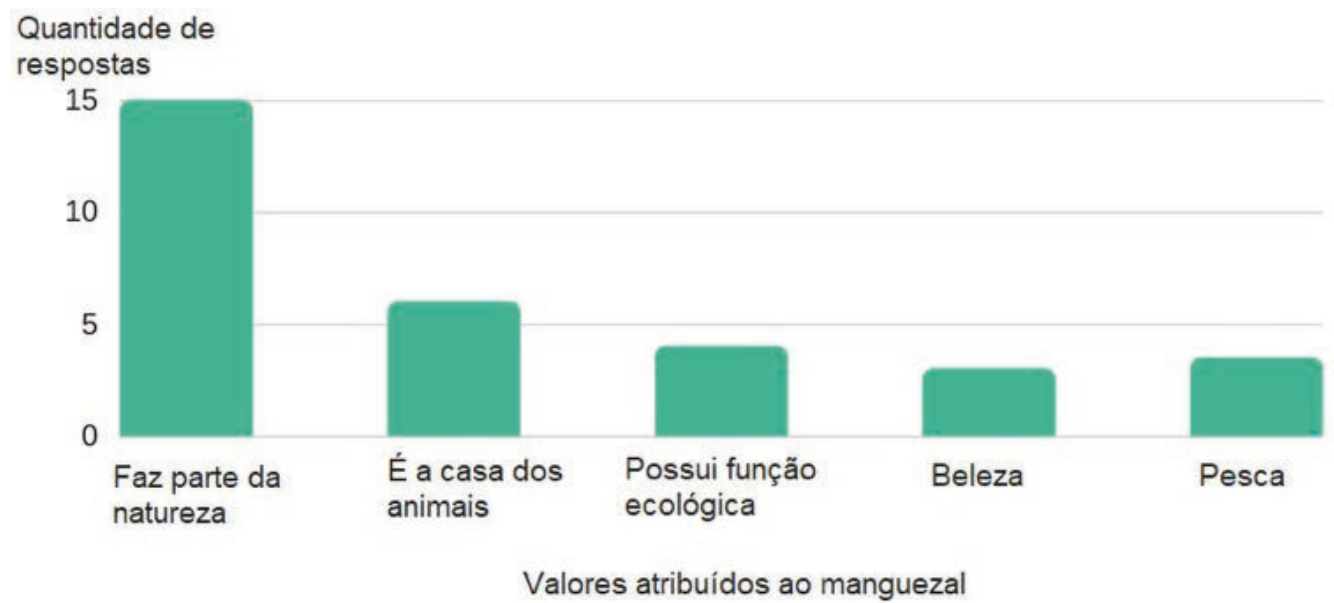

Figura 4 - Número de respostas sobre valores atribuídos ao manguezal Fonte: Autoras.

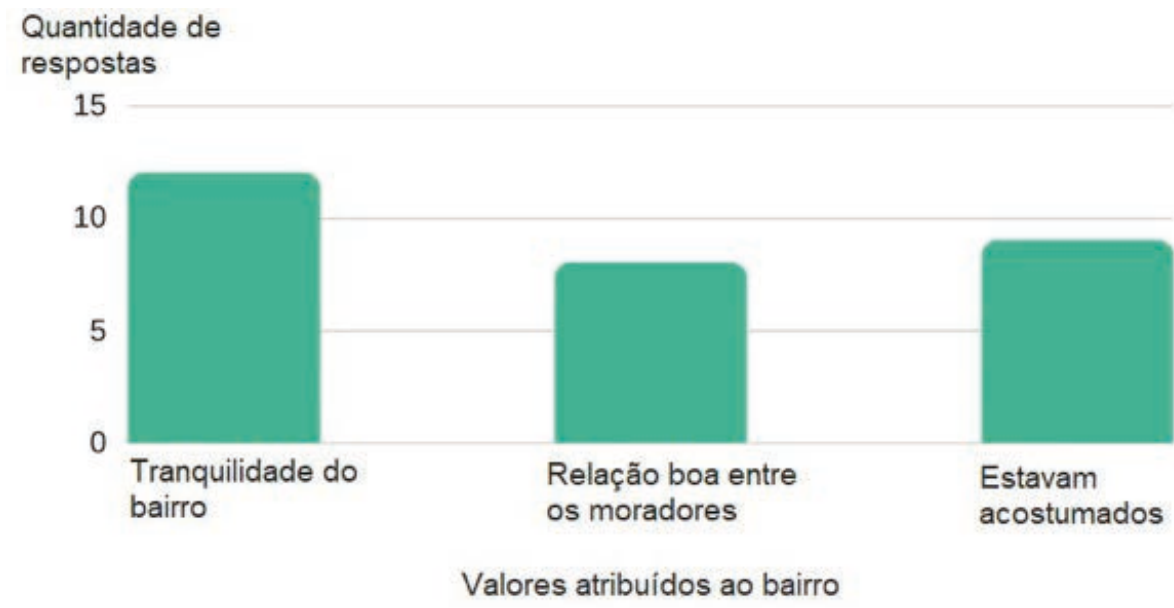

Figura 5 - Número de respostas de valores atribuídos ao bairro.

Fonte: Autoras.

No domínio das atitudes, $73 \%$ da amostra considerou importante cuidar do manguezal do bairro. Ao serem questionados sobre o motivo dessa atitude, muitos investigados referiram importância da manutenção, da limpeza e da beleza do bairro; também houve indicativos de que consideravam o manguezal como um ecossistema com importantes funções ecológicas.

Todos se mostraram a favor da regularização das moradias, e a maioria acreditava que essa regularização poderia trazer benefícios tanto para os moradores como para o ecossistema. Ao serem indagados se consideravam que os moradores causavam algum tipo de impacto no manguezal, $63 \%$ da amostra concordou, citando o desmatamento para construção de casas e a poluição. 
A Figura 6 e a Figura 7 expõem dados absolutos (número de respostas) sobre os motivos para a importância de cuidar do manguezal e benefícios da regularização das moradias, respectivamente.

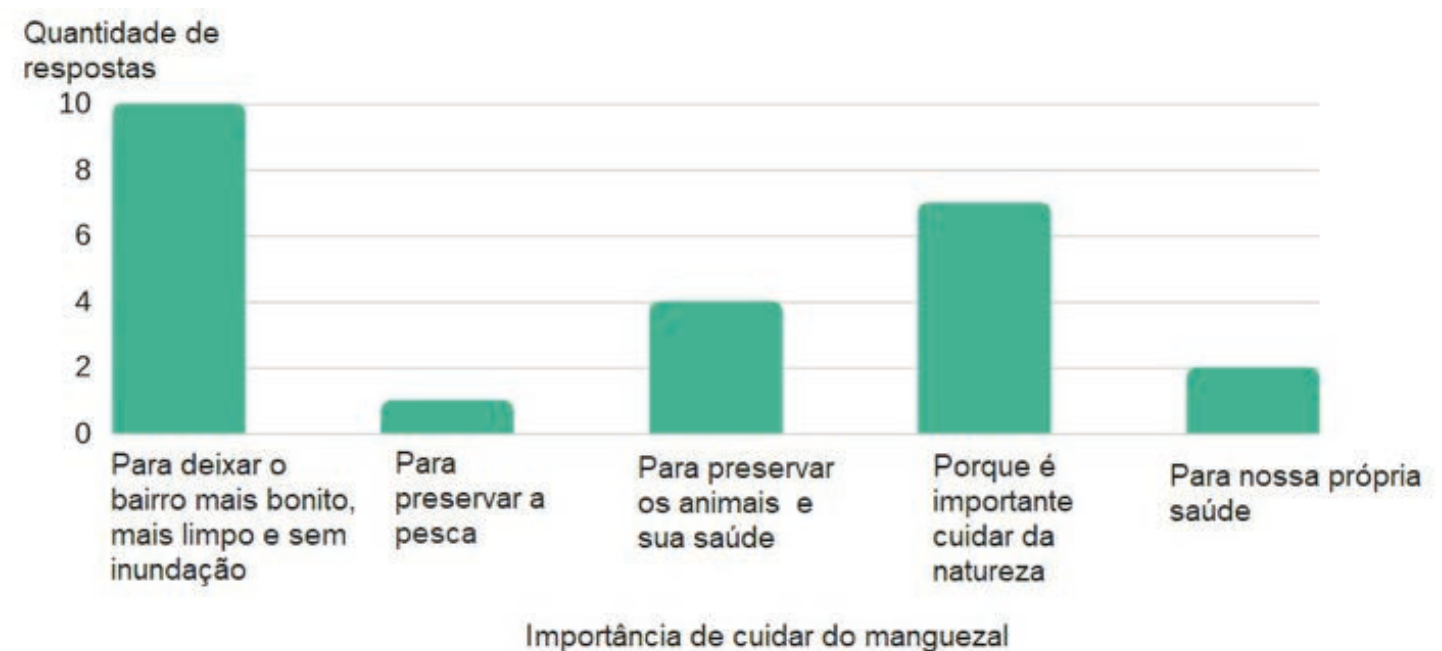

Figura 6 - Número de respostas sobre os motivos para a importância de cuidar do manguezal

Fonte:Autoras.

\section{Quantidade de respostas}

15

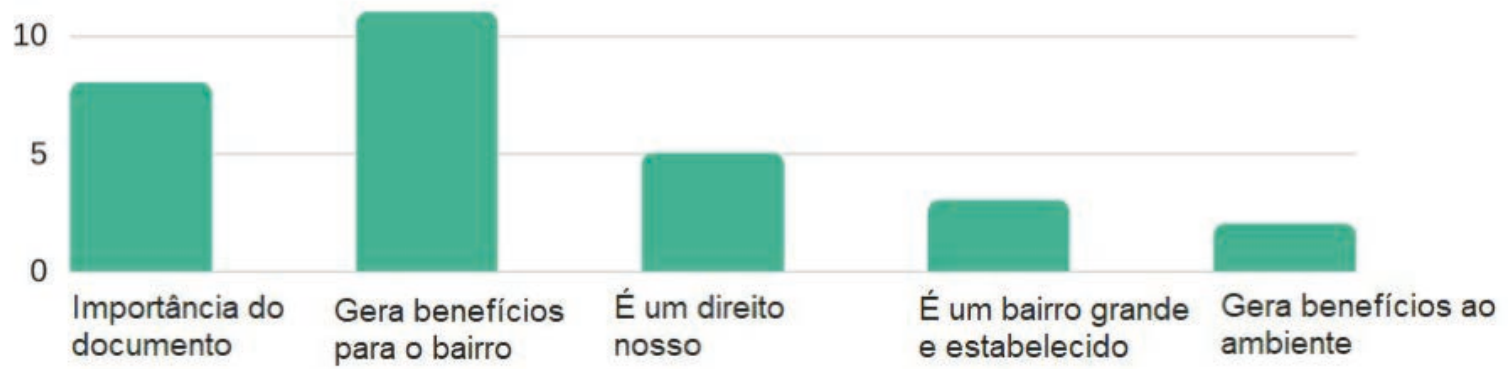

Benefícios da regularização das moradias

Figura 7 - Número de respostas sobre os benefícios da regularização das moradias.

Fonte:Autoras.

A avaliação sobre qualidade de vida da amostra indicou boa classificação em três domínios: físico (em relação a desconfortos corporais e energia para o dia a dia, média $=4,34$ ); psicológico (em relação à autoestima e sentimentos positivos, média $=4,00$ ) e de relações sociais (média $=4,19$ ). Por sua vez, o domínio relativo à qualidade do meio ambiente (qualidade ambiental, recursos financeiros, serviços de saúde, transporte e outros relacionados) foi avaliado com classificação regular, obtendo o valor médio de 3,24 .

A avaliação das condições psicológicas (meios adaptativos, problemas internalizantes e problemas externalizantes) indicou tendência a faixas não clínicas da amostra. Apenas mulheres jovens (na faixa de 18 a 39 anos) indicaram problemas internalizantes e externalizantes em faixas limítrofes (escores entre 60 e 63). 
A Tabela 1 exibe resultados descritivos, em médias e desvio-padrão de resultados do ASR, para condições psicológicas da amostra, em termos de meios adaptativos, problemas internalizantes e problemas externalizantes, pelas variáveis: sexo e faixa etária.

Tabela 1 - Condições psicológicas da amostra, segundo ASR.

\begin{tabular}{cccccc}
\hline Sexo & $\begin{array}{c}\text { Faixa } \\
\text { Etária }\end{array}$ & & $\begin{array}{c}\text { Problemas } \\
\text { Internalizantes }\end{array}$ & $\begin{array}{c}\text { Problemas } \\
\text { Externalizantes }\end{array}$ & $\begin{array}{c}\text { Meios } \\
\text { Adaptativos }\end{array}$ \\
\hline Feminino & $18-39$ & Média & $\mathbf{6 0 , 8 6}$ & $\mathbf{6 2 , 0 0}$ & 48,71 \\
& & DP & 9,42 & 11,85 & 7,72 \\
\cline { 2 - 6 } & $40-59$ & Média & 57,50 & 55,75 & 49,88 \\
& & DP & 15,96 & 16,69 & 7,85 \\
\hline Masculino & $18-39$ & Média & 55,71 & 50,86 & 43,86 \\
& & DP & 7,87 & 7,54 & 11,48 \\
\cline { 2 - 6 } & $40-59$ & Média & 51,00 & 52,13 & 45,63 \\
& & DP & 18,84 & 14,88 & 8,91 \\
\hline
\end{tabular}

Fonte: Autoras.

\section{DISCUSSÃO}

Os manguezais são importantes ecossistemas que muitas vezes estão em intensa interação com ambientes de urbanização irregular e não planejada. Essas condições especiais influenciam os habitantes de tais ambientes, e são por elas influenciados no seu cotidiano e no decorrer do tempo. Também dessa constante interação emergem percepções ambientais e características de qualidade de vida, temas deste estudo.

A percepção ambiental foi aqui entendida como a consciência e compreensão do homem do seu meio ambiente (UNESCO, 1971). A qualidade de vida foi tomada como uma autoavaliação feita a partir dos padrões e expectativas de vida dos próprios indivíduos (THE WHOQOL GROUP, 1995). Por fim, as condições psicológicas foram apreendidas como os recursos (competências) e também disfunções (problemas psicológicos) em diferentes domínios (como os cognitivos e psicossociais) que emergem dessas interações da pessoa com os diferentes sistemas ambientais, desde os mais proximais até os referentes à cultura e momento histórico (BRONFENBRENNER, 2002).

Especificamente quanto à percepção ambiental, no domínio de informação, aqui voltada para aspectos da legislação pertinente àquela área de residência, os resultados mostraram, em sua diversidade, que os investigados possuíam conhecimentos frágeis e truncados sobre aspectos legais do ecossistema de manguezal. Alguns deles sabiam que o manguezal do bairro era protegido por lei ambiental, embora esse conhecimento indicasse ser fragmentado.

Os sistemas jurídicos que protegem esse ecossistema são o Código Florestal (BRASIL, 2012), por ser uma Área de Preservação Permanente, e o Sistema Nacional de Unidades de Conservação (BRASIL, 2000), já que também se trata de um Parque Ecológico Municipal. Compondo parte do conjunto de informações daqueles moradores pesquisados, essas leis não pareceram conhecidas, embora citações tenham ocorrido a respeito do Sistema Nacional de Meio Ambiente (Sisnama) e também de órgãos fiscalizadores, como a Polícia Ambiental e Marinha do Brasil. Esses últimos elementos de informação, de certa forma, correspondem a uma informação legítima, já que tanto o Sisnama como a Marinha possuem competências de instrumentalização de leis voltadas a esse ecossistema. As informações verificadas pareciam ter fonte empírica (e não institucional), originadas de observações do cotidiano, em geral de fiscalizações realizadas por funcionários da prefeitura municipal. 
Existe pouca fiscalização ambiental nas áreas desse manguezal do município de Praia Grande, fato que possibilitou a consolidação daquelas moradias irregulares (LUZ, 2006). Contudo, o início do processo de regularização fundiária trouxe ao bairro intervenções frequentes de representantes da prefeitura e possivelmente dos órgãos fiscalizadores durante o desenvolvimento dos estudos ambientais necessários e na instalação da infraestrutura básica urbana. Isso possibilitou contato direto desses órgãos com os participantes do estudo, provavelmente tendo contribuído com o conjunto de informações identificado. Entretanto, esse contato pareceu insuficiente para apropriação de informações necessárias e pertinentes ao território que habitavam.

Já no domínio sensorial da percepção ambiental dos investigados, foram amplas e expressivas as referências a animais e plantas presentes no manguezal do bairro, com citações de diversidade de espécies. Apesar de os investigados não indicarem o uso da fauna e flora, não havendo, portanto, valor econômico para a população, esse dado pode ser refletido a partir de Tuan (1980) em sua afirmação de que o contato direto com o ambiente ao longo do tempo gera sentimentos de familiaridade que podem resultar na afeição ou desprezo pelo lugar (TUAN, 1980). Habitando o bairro há quase três décadas, a maioria dos pesquisados atribuíram valores positivos àquele ecossistema, indicando uma familiaridade construída que pode ter contribuído para essa maior riqueza da percepção ambiental sensorial, sem utilização mais direta de elementos do ecossistema. Nesse sentido, na percepção ambiental emergiram elementos positivos integrados aos domínios sensorial e valorativo.

No domínio dos valores da percepção ambiental, a maioria dos investigados atribuiu valor positivo ao manguezal, especialmente em função ecológica de integração com a natureza. Para Coelho, Gouveia e Milfont (2006), o valor de "autotranscendência", com orientação universalista, é o principal valor humano, associado a comportamentos pró-ambientais. Por isso, embora sem benefícios econômicos, o reconhecimento da importância ecológica do manguezal para esses habitantes pode ser advindo dessa orientação universalista, que vem sendo disseminada na cultura ocidental a partir da década de 1970, com as primeiras discussões internacionais a respeito do desenvolvimento sustentável e limites de uso dos recursos do planeta (COELHO; GOUVEIA; MILFONT, 2006).

Valores positivos do bairro, por sua tranquilidade e por características de boa vizinhança, também compuseram a percepção ambiental valorativa dos investigados. Retomando Tuan (1980), populações na base das classes econômicas costumam ampliar o sentimento de "lar" para além da casa, abrangendo os espaços públicos do bairro, e ao avaliarem a qualidade do ambiente tendem a levar mais em consideração as relações de afetuosidade com os vizinhos do que as características físicas. A amostra aqui investigada possuía prevalência de integrantes das classes econômicas D e E.

Nesse domínio das atitudes da percepção ambiental, foi marcante a referência da importância do cuidado do manguezal, principalmente para a manutenção da limpeza e beleza do bairro. Essas referências atitudinais indicaram integração mais direta com elementos do domínio valorativo da percepção ambiental. Dessa maneira, uma valoração ambiental positiva poderia se associar a valores de "autopromoção" (COELHO; GOUVEIA; MILFONT, 2006), advindos de interesses pessoais de morar em um bairro limpo e bonito. Barboza e Arruda-Filho (2012) também apontam categorias de caráter hedônico em "consumidores verdes", que optam por serviços ambientalmente corretos por eles proporcionarem prazer e satisfação pessoal ao usuário.

Ao lado dessa condição atitudinal mais positiva, por outro rumo, a maior parte dos investigados afirmou que os moradores causavam impactos negativos ao manguezal do bairro, citando o desmatamento para construção de casas e poluição. Eles não se incluíam na condição de portadores dessas atitudes negativas - eram os outros e não eles quem causavam os impactos. Esse dado também pode evocar uma incongruência entre a atitude de querer cuidar do manguezal, na esfera de fronteira com valores, e atitudes de impactos negativos, na esfera das ações. Problemas de desmatamento e poluição pareciam associados à falta de melhores condições econômicas para habitar outro lugar e a falhas de infraestrutura no bairro (no sistema de esgoto e coleta seletiva), e não por uma escolha consciente dos moradores. 
Ainda no tocante ao domínio atitudinal da percepção ambiental, todos os investigados mostraramse a favor da regularização das moradias, entendendo que ela poderia trazer benefícios tanto para os moradores como para o ecossistema. Embora haja referências de que moradores de ocupações irregulares possuam atitudes ambientais destrutivas por não dependerem do ecossistema invadido para suas atividades econômicas e culturais (SALES; SILVA; CLEMENTINO, 2006), os investigados neste estudo indicaram um conjunto de referências positivas de atitudes pró-ambientais, de conservação e de cuidado, que podem ser atribuídas a valores de autotranscendência ou de autopromoção, como acima referido.

A segunda frente da investigação, a de levantamento de indicadores de qualidade de vida, avaliada pelo instrumento Whoqol-bref, mostrou resultados positivos ("bons") em três dos quatro domínios de verificação do instrumento. Foram considerados "bons" os domínios de natureza física, psicológica e de relações sociais. Apenas o domínio de meio ambiente recebeu avaliação "regular". Sales, Silva e Clementino (2006) indicam que moradores de ocupações irregulares podem ter uma menor qualidade de vida por conta da falta de acesso à infraestrutura adequada. Por outro lado, a vinda de benefícios de infraestrutura para o bairro, com o início da regularização fundiária oficializada em 2013 pela Lei Complementar no 671 (PRAIA GRANDE, 2013), pode ter melhorado os índices de qualidade de vida do local.

Nesse domínio de qualidade de vida referente ao meio ambiente (ressalte-se que foi o único avaliado como "regular" pelos participantes), as questões do instrumento propõem elementos relativos à saúde do ambiente (clima, poluição e barulho) e também de condições financeiras. Esses dados foram avaliados pela maioria dos investigados como "muito baixos" ou "inexistentes". Por sua vez, outros elementos propostos nesse quesito de qualidade de vida ambiental (como segurança, lazer, satisfação com as condições de moradia e serviços de saúde e transporte) foram avaliados mais positivamente pelos participantes. Tais resultados podem indicar que aqueles moradores estivessem satisfeitos com as condições do local onde viviam, embora não as considerassem saudáveis e que seus recursos financeiros fossem insuficientes para suprir todas as suas necessidades, indicando um ideal de padrão de vida baixo na população.

A terceira e última frente do levantamento de condições psicossociais daqueles habitantes de área de ocupação irregular, em manguezal, voltou-se para avaliação de condições psicológicas referentes a competências e a problemas emocionais e comportamentais. De forma geral, os resultados dessa avaliação indicaram valores dentro da normalidade, nos investigados, sem maiores indicativos de preocupações clínicas. Somente em mulheres jovens da amostra (sete indivíduos entre 18 a 39 anos) houve resultados em faixa limítrofe para problemas internalizantes (emocionais) e externalizantes (comportamentais).

A maior parte dos moradores pesquisados declarou estar no mercado de trabalho formal, com exceção das mulheres jovens (apenas duas declararam estar trabalhando), dado que vai ao encontro de Santana et al. (1997) quando afirmaram que pessoas fora do mercado de trabalho formal costumavam ter maior propensão a problemas psicológicos. Ainda, quatro das mulheres jovens eram casadas e declararam como profissão serem donas de casa (enquanto apenas duas das mulheres acima de 40 anos declararam essa condição como profissão). De acordo com Senicato (2015), donas de casa possuem maior prevalência de problemas emocionais e mentais do que mulheres empregadas, possivelmente por conta da rotina de tarefas considerada pesada e monótona, sendo essa diferença agravada em classes econômicas mais baixas.

\section{CONSIDERAÇÕES FINAIS}

Dentro da limitação própria deste estudo em termos amostrais, a triangulação de positividade na percepção ambiental (com valores positivos), na qualidade de vida e em condições psicológicas, indicou uma relação equilibrada entre os indivíduos pesquisados e o meio ambiente. Esse resultado contraria outras contribuições da literatura, nas quais se sugere o desequilíbrio em populações irregulares em áreas de manguezais (SALES; SILVA; CLEMENTINO, 2006). 
Grande parte da amostra do presente estudo conseguiu relacionar a importância de um ambiente ecologicamente saudável com seu bem-estar. De forma geral, os participantes revelaram possuir uma compreensão aguçada do manguezal pelo conhecimento de vários de seus componentes, atribuindo valores positivos aos benefícios do ecossistema, e reconhecendo a importância de atitudes conservacionistas. Ao longo do tempo, essas atitudes podem favorecer o alcance de melhores condições de equilíbrio ao manguezal remanescente do bairro, que em contato direto com os moradores, pode, por sua vez, acrescentar melhorias na saúde e qualidade de vida. Pela avaliação realizada neste estudo, elementos dessas tendências positivas de qualidade de vida já foram detectados nos investigados e podem ser decorrentes de melhorias nas condições ambientais promovidas pela regularização fundiária em curso. Segundo a Lei Complementar no 671 (PRAIA GRANDE, 2013), as ações dessa regulamentação têm previsão de término para 2022, quando poderá ser oportuna uma nova investigação a respeito do aqui pesquisado.

Seria uma percepção ambiental acentuada a respeito da importância do manguezal relacionada a condições de positividade na vida dos moradores investigados? Outros estudos poderão buscar melhor qualidade nesse entendimento, até com incorporação de contribuições de abordagens fenomenológicas, aquelas que ressaltam a importância de contatos prévios com a população investigada para evitar indagações formuladas apenas a partir da literatura (SOUZA, 2017).

Espera-se que um levantamento de suas percepções do ambiente, além de dados de seus perfis emocionais e qualidade de suas vidas, contribua para um melhor entendimento dos perfis desses habitantes, o que poderá subsidiar possíveis intervenções voltadas ao desenvolvimento positivo do ecossistema de manguezais ocupados por habitantes não pertencentes a populações tradicionais.

\section{REFERÊNCIAS}

ACHENBACH, T. M.; RESCORLA, L. A. Multicultural Supplement to the Manual for the ASEBA Preschool Forms \& Profiles. Burlington, VT: University of Vermont, Research Center for Children, Youth, \& Families. 2010.

ALVES, J. R. P. (Org.). Manguezais: educar para proteger. Rio de Janeiro: Femar/Semads, 2001. Disponível em: <http://www.mma.gov.br/estruturas/sqa_pnla/_arquivos/manguezais.pdf>. Acesso em: 5 out. 2017.

ARASAKI, E. et al. Os efeitos no ambiente marinho da elevação do nível do mar em regiões da Baixada Santista, Brasil. Revista Brasileira de Recursos Hídricos, v. 13, p. 165-175, 2008.

ASSOCIAÇÃO BRASILEIRA DE EMPRESAS DE PESQUISA. Critério de Classificação Econômica Brasil, 2015. Disponível em: <http://www.abep.org/criterio-brasil>. Acesso em: 5 out. 2017.

BARBOZA, M. N. L.; ARRUDA FILHO, E. J. M. O comportamento do consumidor tecnológico diante dos valores ecologicamente corretos: ideologia verde versus responsabilidade social. Intercom - Revista Brasileira de Ciências da Comunicação, v. 35, p. 157-182, 2012.

BARDIN, L. Análise de conteúdo. 4. ed. Lisboa: Edições 70, 2010.

BORGES, L. A. C.; REZENDE, J. L. P.; COELHO JÚNIOR, L. M. Aspectos técnicos e legais que fundamentam o estabelecimento das APP nas zonas costeiras - Restingas, Dunas e Manguezais. Revista de Gestão Costeira Integrada, v. 9, p. 39-56, 2008. Disponível em: <http://lawww.redalyc.org/articulo. oa?id=388340125004>. Acesso em: 5 out. 2017.

BRASIL. Lei no 9.985, de 18 de julho de 2000: Regulamenta o art. 225, § 10, incisos I, II, III e VII da Constituição Federal, institui o Sistema Nacional de Unidades de Conservação da Natureza e dá outras providências. Diário Oficial [da] República Federativa do Brasil, Poder Executivo, Brasília, 19 jul. 2000. Disponível em: <http://www.planalto.gov.br/ccivil_03/leis/L9985.htm>. Acesso em: 5 out. 2017. Brasília, 2000. 
BRASIL. Lei №. 12.651, de 25 de maio de 2012. Dispõe sobre a proteção da vegetação nativa; altera as Leis no 6.938, de 31 de agosto de 1981, 9.393, de 19 de dezembro de 1996, e 11.428, de 22 de dezembro de 2006; revoga as Leis no 4.771, de 15 de setembro de 1965, e 7.754, de 14 de abril de 1989, e a Medida Provisória no 2.166-67, de 24 de agosto de 2001; e dá outras providências. Diário Oficial [da] República Federativa do Brasil, Poder Executivo, Brasília, 28 mai. 2012. Disponível em: <http:// www.planalto.gov.br/ccivil_03/_ato2011-2014/2012/lei/l12651.htm>. Acesso em: 5 out. 2017.

BRONFENBRENNER, U. A ecologia do desenvolvimento humano: experimentos naturais e planejados. Porto Alegre: Artmed, 2002.

COELHO, J. A. P. M.; GOUVEIA, V. V.; MILFONT, T. L. Valores humanos como explicadores de atitudes ambientais e intenção de comportamento pró-ambiental. Psicologia em Estudo, v. 11, p. 199-207, 2006. Disponível em: <http://www.redalyc.org/articulo.oa?id=287122090023>. Acesso em: 5 out. 2017.

CUNHA-LIGNON, M. L. et al. Estudos de casos nos manguezais do estado de São Paulo (Brasil): aplicações de ferramentas com diferentes escalas espaço-temporais. Revista de Gestão Costeira Integrada, v. 9, p. 79-91, 2009.

HARTIG, T. et al. Nature and health. Annual Review of Public Health, v. 35, p. 207-228, 2014.

IVANOVA, M. Y. et al. Syndromes of self-reported psychopathology for ages 18-59 in 29 societies. Journal of Psychopathology and Behavioral Assessment, v. 37, p. 171-183, 2015.

LIMA, C. O.; OLIVEIRA, R. C. Análise ambiental de ocupação nas áreas de manguezais no município de Santos-SP. Revista Geográfica de América Central, v. 2, p. 1-13, 2011. Disponível em: <http://www. revistas.una.ac.cr/index.php/geografica/article/view/2552/2438>. Acesso em: 5 out. 2017.

LUCENA, M. M.; FREIRE, E. M. Percepção ambiental como instrumento de participação social na proposição de área prioritária no semiárido. Revista Internacional Interdisciplinar INTERthesis, v. 11, p. 147-171, 2014.

LUCENA-SANTOS, P.; MORAES, J. F. D.; OLIVEIRA, M. S. Análise da estrutura fatorial das escalas sindrômicas do ASR (Adult Self-Report). Revista Interamericana de Psicologia, v. 48, p. 252-264, 2014. Disponível em: <http://www.redalyc.org/pdf/284/28437897002.pdf>. Acesso em: 5 out. 2017.

LUZ, N. C. Diagnóstico dos aspectos do meio físico em áreas de manguezal, Parque Piaçabuçu - Praia Grande/SP e sua relação com a ocupação por favelas. Dissertação (Mestrado em Engenharia Urbana) - Centro de Ciências Exatas e de Tecnologia - Universidade Federal de São Carlos, São Carlos, 2006.

MARIN, A. A. Pesquisa em educação ambiental e percepção ambiental. Pesquisa em Educação Ambiental, v. 3, p. 203-222, 2008.

MENEZES, G. V. et al. Recuperação de manguezais: um estudo de caso na Baixada Santista de São Paulo, Brasil. Brazilian Journal of Aquatic Science and Technology, v. 9, p. 67-74, 2005.

MOREIRA JÚNIOR, W.; CASTRO, M. P. G.; MENEZES, L. C. B. A explotação dos manguezais da Baixada Santista - SP através das comunidades locais. CONGRESSO DE MEIO AMBIENTE DA ASSOCIAÇÃO DE UNIVERSIDADES GRUPO DE MONTEVIDÉU, São Carlos, SP, Brasil, 6, 2009. Disponível em: <http://www. ambiente-augm.ufscar.br/uploads/A3-123.pdf>. Acesso em: 11 set. 2017.

ORGANIZAÇÃO DAS NAÇÕES UNIDAS PARA A EDUCAÇÃO, A CIÊNCIA E A CULTURA. 1st International co-ordinating council of the programme on man and the biosphere (MAB). Paris: MAB Report Series, 1971. Disponível em: <http://npshistory.com/publications/mab/unesco-mab-report/1.pdf >. Acesso em: 5 out. 2017.

PALMA, I. R. Análise de percepção ambiental como instrumento ao planejamento da educação ambiental. Dissertação (Mestrado em Engenharia), Programa de Pós-Graduação em Engenharia 
de Minas, Metalúrgica e de Materiais - Universidade Federal do Rio Grande do Sul, Porto Alegre, 2005. Disponível em: <http://www.lume.ufrgs.br/bitstream/handle/10183/7708/000554402. pdf?sequence=1>. Acesso em: 5 out. 2017.

PEREIRA, R. J. et al. Contribuição dos domínios físico, social, psicológico e ambiental para a qualidade de vida global de idosos. Revista de Psiquiatria do Rio Grande do Sul, v. 28, p. 27-38, 2006.

PRAIA GRANDE. Lei no 473, de 27 de dezembro de 2006. Aprova a Revisão do Plano Diretor da Estância Balneária de Praia Grande para o período de 2007 a 2016. Secretaria de Administração, Praia Grande, 27 dez. 2006. Disponível em: <http://www.praiagrande.sp.gov.br/arquivos/leisdecretos/2616.pdf>. Acesso em: 5 out. 2017.

PRAIA GRANDE. Lei no 671, de dezembro de 2013. Institui o Programa de Regularização Fundiária no Município de Praia Grande, e dá outras providências. Secretaria de Administração, Praia Grande, 12 dez. 2013. Disponível em: <http://www.praiagrande.sp.gov.br/Administracao/leisdecretos_view. asp?codLeis $=4480 \&$ Acao=busca $>$. Acesso em: 5 out. 2017.

QUEIROZ, L. S.; MEIRELES, A. J. A.; HERAS, S. R. Serviços ecossistêmicos costeiros e comunidades tradicionais. Revista da Ampege, v. 8, p. 145-159, 2012.

ROCHA, M. M.; GAUY, F. V.; SILVARES, E. F. M. Uma comparação da autoavaliação do adulto/cliente com a de seu terapeuta. 42a REUNIÃO ANUAL DA SOCIEDADE BRASILEIRA DE PSICOLOGIA E VIII CONGRESSO IBEROAMERICANO DE PSICOLOGIA, São Paulo, 2012.

SALES, L. G. L.; SILVA, R. M. M.; CLEMENTINO, M. L. M. Da natureza natural à natureza social: os caminhos da relação entre sociedade e mangue de Bayeux - PB. III ENCONTRO DA ANPPAS, Brasília, 3, 2006. Disponível em: <http://www.anppas.org.br/encontro_anual/encontro3/arquivos/TA20904032006-024459.DOC>. Acesso em: 11 set. 2017.

SANTANA, V. S. et al. Informal jobs: another occupational hazard for women's mental health? International Journal of Epidemiological, v. 26, p. 1236-1242, 1997. Disponível em: <https://goo.gl/ VeZgN9>. Acesso em: 5 out. 2017.

SÃO PAULO. (Estado). Secretaria da Habitação. Regularização Fundiária beneficia mais de 8 mil pessoas em Praia Grande. Notícias, 2 mai. 2016. Disponível em:<http://www.habitacao.sp.gov.br/noticias/ viewer.aspx?ld=5923>. Acesso em: 20 set. 2017.

SÃO PAULO. (Estado). Secretaria do Meio Ambiente. ZEE Baixada Santista: zoneamento ecológicoeconômico setor costeiro da Baixada Santista. São Paulo: SMA, 2013. Disponível em: <http://arquivos. ambiente.sp.gov.br/cpla/2011/05/ZEE_PUBLICACAO.pdf>. Acesso em: 5 out. 2017.

SENICATO, C. Saúde e trabalho em mulheres adultas: estudo de base populacional no município de Campinas, São Paulo. Tese (Doutorado em Saúde Coletiva) - Faculdade de Ciências Médicas Universidade Estadual de Campinas, Campinas, 2015. Disponível em:<http://repositorio.unicamp.br/ bitstream/REPOSIP/312915/1/Senicato_Caroline_D.pdf>. Acesso em: 5 out. 2017.

SOUZA, L. B. Percepção ambiental e fenomenologia: possibilidades de adaptação do método e alguns exemplos de pesquisas. Desenvolvimento e Meio Ambiente, v. 40, p. 297-314, 2017.

THE WHOQOL GROUP. The World Health Organization quality of life assessment (WHOQOL): position paper from the World Health Organization. Social Science \& Medicine, v. 41, p. 1403-1409, 1995.

TUAN, Y. F. Topofilia: um estudo da percepção, atitudes e valores do meio ambiente. Rio de Janeiro: Difel, 1980.

WHITE, M. P. et al. The "Blue Gym": what can blue space do for you and what can you do for blue space? Journal of the Marine Biological Association of the United Kingdom, v. 96, p. 5-12, 2016. 
WHYTE, A. V. T. La Perception de environnement: lignes directrices méthodologiques pour les études sur le terrain. Paris: Unesco, 1978. Disponível em: <http://unesdoc.unesco.org/ images/0002/000247/024707fo.pdf>. Acesso em: 5 out. 2017.

Guidelines for field studies in environmental perception. Paris: Unesco, 1977. Disponível em: <http://unesdoc.unesco.org/images/0002/000247/024707eo.pdf>. Acesso em: 5 out. 2017. 